\title{
Facilitating and Measuring Older People's Creative Engagement in a User Centred Design Process
}

\author{
Helena Sustar \\ PhD Research student \\ City University London \\ School of Informatics \\ Centre for $\mathrm{HCl}$ Design \\ helena.sustar.1@ @ity.ac.uk
}

\begin{abstract}
The goal of my $\mathrm{PhD}$ is to research the relationship between creativity and age in the user centred design (UCD) process for user interfaces. To assess this, a comparative study will be conducted. First a UCD process with group of older people future consumers (mainly 60+) will be run. Then the results from this group will be compared with sessions I will run with Human Computer Interaction (HCI) design students. Finally the same study will be conducted with mixed generation groups. The participants will be involved in two stages of the UCD process: in a contextual enquiry stage and in a prototyping stage. Throughout the process creativity, motivation and methodology adoption will be measured and compared across groups. As a result of this study new (or adapted) methodologies for encouraging creative participation of older people in the UCD process will be developed. This will be a valuable contribution to the HCI design field, as it will provide guidance on how to more effectively involve older people in the UCD process.
\end{abstract}

ACM Classification Keywords: H5.m. Information interfaces and presentation (e.g., HCI): Miscellaneous: K4.2. Computers and society: Social issues

Keywords: Older people, creativity, co-design, cultural probes, participatory design, methodology

\section{PROBLEM STATEMENT}

Interfaces and products are usually designed for a broad market and general use by younger users [5]. In the classic design process used by design agencies, older people are rarely involved, or if they are, they are brought in at the end of the design cycle as participants in usability tests. A preliminary study I conducted showed that this often results in low acceptability of the final product by older people. Others have looked at how to involve older people in the design process of Web sites and interfaces, healthcare systems, personal calendars, interactive organization of photos, assistive technology applications and computer games [7, 8, 9]. The Helen Hamlyn Research Centre regularly involves older people in their inclusive design projects [1] often in a participatory design setting [4]. Also the Utopia project used

(c) The Author 2008.

Published by the British Computer Society adaptations of traditional methodologies: interviews, focus groups, diary, workshops and questionnaires with older people [3]. Still others have used design probes [6] as a means of involving older people in the design process.

Older people have huge creative potential. Cropley [2] found that there is a high level of creativity even in old age. Lindauer [9], who investigated the creativity of older artists, found that their creative span is longer and their artwork improved as they aged.

Despite the fact that there is existing research that (a) looked at the involvement of older people in participatory design activities, and (b) supports the creative potential of older people, there is no research that looks at combining the two themes i.e. at ways of facilitating and measuring creative involvement of older people in participatory design activities. The goal of my $\mathrm{PhD}$ is to address this limitation in the HCI research literature.

\section{AIMS AND OBJECTIVES}

The overall aim of my research is to study how best to facilitate and measure creative involvement of older people in the UCD process of designing user interfaces. More specifically, I aim to:

1. How creative are certain age groups in the UCD process and how to measure their degree of creative engagement.

2. Identify which design techniques and methods encourage certain different age groups to participate in the creative design process.

3. Whether mixed generation group design activities can encourage or discourage creative engagement.

\section{COMPLETED WORK}

As a first step I wanted to check whether classic UCD techniques could initiate creative engagement. To achieve this I used UCD methods to design a "Virtual garden" [9] (see Figure 1 left). The idea was to design a simple and intuitive interface with technology and wireless media. The main interactions happened between the user and device by touching the "plants" - gadgets, and changing their position in the garden. Some of the gadgets like the communication devices follow a wearable interface style. The prototype has been used in a usability evaluation pilot project with users where I explored how potential users would accept the "Virtual garden". Three different age groups of users were chosen: students (23+), older people in their sixties, and older people in their eighties. A series of interviews based around interacting with the prototype were conducted. We tried to find out how familiar the participants were with certain parts of the device, their opinions about colours, shapes and materials used. In addition, we asked them to place 
themselves in different situations: having a conversation with a friend, taking medicine, being reminded of daily activities, managing the household (as in a smart house) and thinking how a device could provide different services to support these situations [9]. I was especially interested to find out: (a) whether users found this interaction style appropriate (b) how successful was the device in supporting users' tasks (c) what was the role of the model in stimulating new ideas and what kind of ideas the model generated and (d) what were the main difficulties that block creativity.

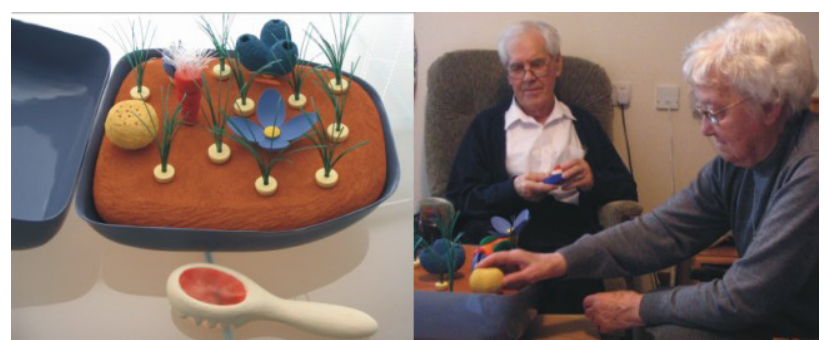

Figure 1 Left: The prototype named "Virtual garden with associated gadgets. Right: Interaction with the prototype boosts many new ideas at all age groups.

The results of the qualitative research (See Figure 1 right) showed some similar characteristics for all age groups: identifying the prototype as a toy rather than a serious interaction device and commenting on whether the prototype could provide more interaction: voice, smell, glowing and changing of colours. Students seemed to enjoy this specific interaction with the garden. For the 60+ group the device was perceived as being too simplistic, they expected more advanced technology and more realistic devices. The participants in their 80 s seemed to have more solid patterns of using traditional technology and were more resistant to accepting new modes of interaction. The reason for this may be their exclusion from using and having experience with the newest technology, which we can call the 'technological gap'. New ideas were stimulated both by the prototype itself and by the participants' interaction with it. For example, new ideas came out from: the garden and kitchen utensils, existing and future technology. There were three main reasons why new ideas had difficulty to develop regardless of age. Firstly, either too many existing experiences or in some cases lack of experience was a block to creativity: thus experience wins over creativity. Secondly, participants seemed incapable of imagining different possibilities. We assumed this was because of the low functionality of the prototype. Finally, a number of participants seemed convinced that a device such as this one was more appropriate for an age group different than their own.

\section{FUTURE WORK}

From the completed work I identified that more work needs to be done to understand better how creativity could be facilitated and manifested with older people. In addition it was obvious to me that existing classic design/evaluation methods are weak at encouraging creative engagement with older people. To address this, I plan to conduct the following studies:

1. In order to get a full understanding of the creative potential of older people, I have begun to observe how older people interact in group activities (mostly not formal ones - e.g. social events).

2. I plan to explore the use of innovative methods, such us design probes [6], as an approach to helping older participants to make a shift from experience to creativity. It is also expected that these methods might encourage them to think creatively by making use of their life experiences and daily activities. The choice of methods will depend on the results from the observation described in activity 1 .

3. After completing activities 1 and 2, I plan to develop new methods of participatory design with older people, such as creativity workshops. The goal will be to actively and creatively involve older people in design. A combination of single and mixed generation group activities will be carried out with students and $60+$ groups.

4. The results from activities 1-3 will help me to identify how best to facilitate and measure the creative involvement of older people in the UCD process of designing user interfaces, by being identifying which creative methods best fit the way of thinking of older people.

\section{CONTRIBUTION TO THE HCI DESIGN FIELD}

As I mentioned in the introduction, although other researchers have involved older people in UCD activities, and although others have identified creative potential in older people, nobody has explored how we can creatively involve older people in UCD, and my aim is to do that. In this paper I described a series of activities that I completed or plan to complete as part of my PhD to achieve this aim.

\section{ACKNOWLEDGEMNT}

The author thanks both supervisors Dr. Zaphiris and Dr. Jones for their constructive discussions, feedbacks and strong support.

\section{References}

[1] Coleman R.2003. Living longer-the new context for design:http://www.designcouncil.org.uk/resources/assets/ assets/pdf/Living\%20Longer.pdf (Accessed May 19, 2004)

[2] Cropley A. 2008. Creative Performance in Older Adults, University of Hamburg, Department of Psychology http://www.waxmann.com/fs/cropley.pdf (Accessed February 24, 2008)

[3] Eisma R., Dickinson A., Goodman J, Mival O., Syme A. \& Tiwari L. 2003. Mutual inspiration in the development of new technology for older people In: Include 2003, London, March 2003, 252-259.

[4] Gaver B., Dunne T., Pacenti E.1999. Cultural Probes, Interaction, January-February 1999, 21-29.

[5] Gregor P.\& Newell A.F., Zajicek M. 2001. Designing for Dynamic Diversity - interfaces for older people In Proc. 2001 EC/NSF 90-91

[6] Mattelmäki. T.: Design probes, University of Art and Design Helsinki, Helsinki, Finland (2006), 30.

[7] Lindauer M.S., Orwoll L. \& Kelly M.C. 1997. Aging Artists on the Creativity of Their Old Age, Creativity Research Journal, Vol. 10, No 2\&3, 133-152.

[8] Silva, A.P., Dix A. 2006. Chindogu and Scrapheap Spirit as Creativity Triggers. In Proc. CCID 2006. Leonardo Network. 91-95.

[9] Sustar H., Zaphiris P. 2007. Emotional Interaction as a Way of Communication, In Proc. DPPI 2007, School of Design, University of Art and Design, Helsinki, Finland, 438-445. 